\title{
Study on Functional Layout of Forest Health Care Base Based on Visual Effect of Landscape: A Case Study of Beijing Mangshan National Forest Park
}

\author{
Chaochen Xue ${ }^{1, a}$, Yonggang $A n^{1,2,3, b}{ }^{*}$ \\ ${ }^{1}$ The School of Landscape Architecture, Beijing University of Agriculture \\ ${ }^{2}$ Beijing Laboratory of Urban and Rural Ecological Environment \\ ${ }^{3}$ Beijing Collaborative Innovation Center for Eco-environmental Improvement with Forestry and Fruittree, Beijing University of Agriculture \\ a1227724767@qq.com, bWokaixin75@sina.com \\ ${ }^{*}$ Corresponding author
}

\begin{abstract}
In recent years, with the rapid development of forest health care industry in China, the demand for forest health care base, especially the construction of mountain forest health care base, has become increasingly urgent. Based on the spatial analysis function of GIS software and the impact of mountain forest environmental factors on human health, this paper briefly introduces the main site selection requirements and application of mountain forest recreation base, taking Jixian County as an example.
\end{abstract}

Keywords: Visual effects; Color psychology; Health care layout.

From the perspective of visual aesthetics and psychology, landscape vision is regarded as a factor that affects health. This paper studies people's perceptions of different landscapes, so as to clarify the application of recuperation efficacy in forest recuperation base. Landscape refers to the scenery, scenery and features that can cause people to have good psychological effects in a certain area. How to turn landscape into a valuable convalescent resource is an important research direction in forest conservation.

\section{General situation of Mangshan Forest Park in Beijing}

Beijing Mangshan Forest Park, located in the northeast of Changping County, is 40 kilometers away from Beijing, with a forest area of 6700 hectares. There is a large reservoir in the southwest of the mountain, and there is a pool on the top of the Northeast hill.

\section{Multi view visual analysis}

The structure of Forest Recreation base is mainly divided into the following parts: viewing and browsing area, recreation and oxygen function area, fitness function area and accommodation function area.

\subsection{Elevation analysis}

High altitude area is an open field. Open vision that can bring people a good visual experience, ease the mood, base convalescent area is not here. Attention should be paid to the visibility of sight. Ensure that the line of sight moves from high to low. As shown below, the green line is a visual area. The red line is invisible.

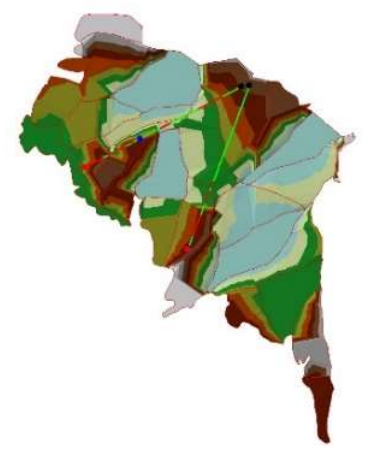

Figure 1. Visibility analysis of Beijing Manshan national Forest Park.

\subsection{Dynamic vision and static vision}


First, the visual analysis of forest landscape based on tour route. In the visual dwesign of forest landscape, roads not only evacuate traffic and guide passenger flow, but also play the role of connecting different spatial sequences. The order of spatial change affects the interest of tourists, because each touch is the aftertaste of the previous scene and the expectation of the next scene, to minimize the impact of human disturbance on forest vegetation. The terrain in a landscape is relatively flat, and the forest is the main factor to guide spatial perception, while the neat, atmospheric and spectacular forest sea is recognized as a beautiful landscape.

In addition to the mobility of space, visual movement and stillness are mainly composed of water. Quiet as water, indifferent and quiet is our pursuit of the artistic concept. Static surface spac enables the convalescents to calm down and say away from the noisy urban environment, so it is an important element of treatment space in mountainous areas. It is necessary to focus on the static water landscape and maintain health starting from the psychological needs of the convalescents. It is an important option for the elderly health care community and medical institutions. The main forms of dynamic water landscape are waterfalls, streams, springs, water fog, etc., which make people feel brightness, change and excitement in form and sense. The flow and impact sound that attracts people's attention can reduce noise, purify the auditory nerve and improve mood. The area of dynamic water can be used as fitness zone, walking area and so on. Water landscape is usually designed at the visual focus of the site or at the intersection of the landscape axis to increase spatial cohesion and attraction. We should pay attention to grasping the spatial scale relationship in the design process, and make use of the difference of mountain height to make the waterscape closer to people, meet people's hydrophilic needs, and help the treatment according to the needs of landscape treatment function.

\subsection{Light environment analysis}

The light environment of forest recreation space needs to be considered in two ways. On the one hand, the main active areas in the recreation area need good lighting, preferably in the south direction with better lighting, and the southeast slope as the main slope of building and site construction. On the other hand, recuperate district also needs to prevent the sun from exploding to prevent glare. Topography and plants can achieve the proper use of natural light, and lighting in buildings is the top priority. There is a more reasonable distribution to avoid excess heat in summer and increase the temperature in winter, so as to collect more light, avoid heat loss, and be conducive to outdoor activities. At the same time, in order to avoid light pollution and radiation, less use of large area of landscape glass windows can effectively resist the generation of glare, people have a healthier light environment.

As shown in the figure below, the light blue area is the key construction area to the south, and also the key area for lighting control of buildings.

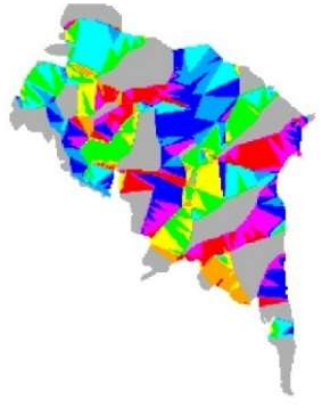

Figure 2. Elevation analysis of Mangshan National Forest Park in Beijing.

\subsection{Color analysis}

Color is one of the important factors that affect people's visual observation. The combination of the inherent color of plants and the intuitive visual experience with seasonal changes. At the same time, the nature of color itself has different psychological effects on people. Therefore, in the design of forest landscape, we should make full use of the seasonal changes of forest stand, construct the characteristic forest landscape, and make the forest landscape "transfer season". ${ }^{[1]}$

Table 1. Color function table.

\begin{tabular}{|c|c|}
\hline Color & Convalescent effect \\
\hline white & $\begin{array}{c}\text { Relieve extreme emotions and } \\
\text { maintain a balance of mentality. }\end{array}$ \\
\hline green & $\begin{array}{c}\text { Fresh and vigorous. A very } \\
\text { pleasing color. It has the } \\
\text { function of stability and } \\
\text { harmony, and helps relieve } \\
\text { depression. }\end{array}$ \\
\hline blue & $\begin{array}{c}\text { Relieving psychological tension } \\
\text { and relieving dryness and heat }\end{array}$ \\
\hline red & $\begin{array}{c}\text { Enthusiastic and bold. It has the } \\
\text { effect of relieving depression. }\end{array}$ \\
\hline yellow & $\begin{array}{c}\text { Bright and healthy. Stabilize } \\
\text { mood and increase appetite }\end{array}$ \\
\hline
\end{tabular}

As shown below, there is a reservoir in the southwest of Mangshan National Forest Park in Beijing, and there is a pool in the northwest. They are all good static landscapes. At the same time, blue can relieve people's mood. The vision location in sanatorium needs to consider two water bodies visually.

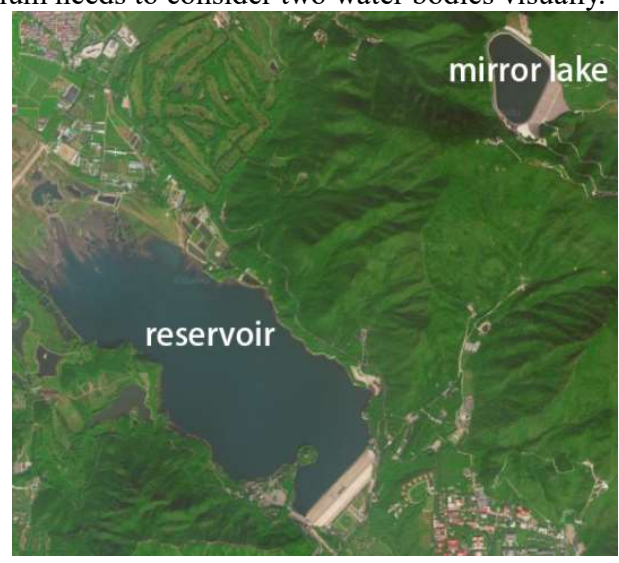

Figure 3. Water distribution of Mangshan National Forest Park in Beijing. 


\section{Development prospect}

The research on planning and design methods of recuperation base should focus on studying the therapeutic space of recuperation base from the visual and visual physiological and psychological perspectives. It will be incorporated into the planning and design system of the whole forest conservation base. As an integral system, the planning and design of recreational base should be based on the types of recreational base, the promotion of recreational factors, physiological and psychological effects, and build a scientific and perfect standard system of planning and design.

\section{Acknowledgement}

Beijing University of Agriculture think tank project; The science and technology innovation service capacity building - fruit industry construction - scientific research base of ecological environment function to enhance the Collaborative Innovation Center (2011 Collaborative Innovation Center) (municipal), 2018 years project code for PXM2018 014207000024; Construction of scientific and technological innovation service capability urban and rural ecological environment Beijing laboratory construction

\section{References}

1. Guo XT. Landscape design of mountain convalescent space. Southwest University (2010)

2. Duan YM, Du SH. Application of GIS technology in mountain planning and design. Planner 11.45-48 (2002)

3. Tan YM.. Research on planning and design of forest health care base (2015)

4. $\mathrm{Lu} \mathrm{L}$. Planning Research on mountain type sightseeing agricultural park. Southwest University (2012)

5. Wang D. Study on the Landscape Planning and Design of Comprehensive Recreational Health Base as basis of Natural Environment-Taking Hanjiang Health Valley Design in Ningqiang County of Hanzhong City as an Example. Gansu Agricultural University (2018) 